\title{
Hybrid-Wing-Body Vehicle Composite Fuselage Analysis and Case Study
}

\author{
Vivek Mukhopadhyay ${ }^{1}$ \\ Aeronautical Systems Analysis Branch, \\ 442/NASA Langley Research Center, Hampton, VA 23681
}

\begin{abstract}
Recent progress in the structural analysis of a Hybrid Wing-Body (HWB) fuselage concept is presented with the objective of structural weight reduction under a set of critical design loads. This pressurized efficient HWB fuselage design is presently being investigated by the NASA Environmentally Responsible Aviation (ERA) project in collaboration with the Boeing Company, Huntington Beach. The Pultruded Rod-Stiffened Efficient Unitized Structure (PRSEUS) composite concept, developed at the Boeing Company, is approximately modeled for an analytical study and finite element analysis. Stiffened plate linear theories are employed for a parametric case study. Maximum deflection and stress levels are obtained with appropriate assumptions for a set of feasible stiffened panel configurations. An analytical parametric case study is presented to examine the effects of discrete stiffener spacing and skin thickness on structural weight, deflection and stress. A finite-element model (FEM) of an integrated fuselage section with bulkhead is developed for an independent assessment. Stress analysis and scenario based case studies are conducted for design improvement. The FEM model specific weight of the improved fuselage concept is computed and compared to previous studies, in order to assess the relative weight/strength advantages of this advanced composite airframe technology.
\end{abstract}

\section{Nomenclature}

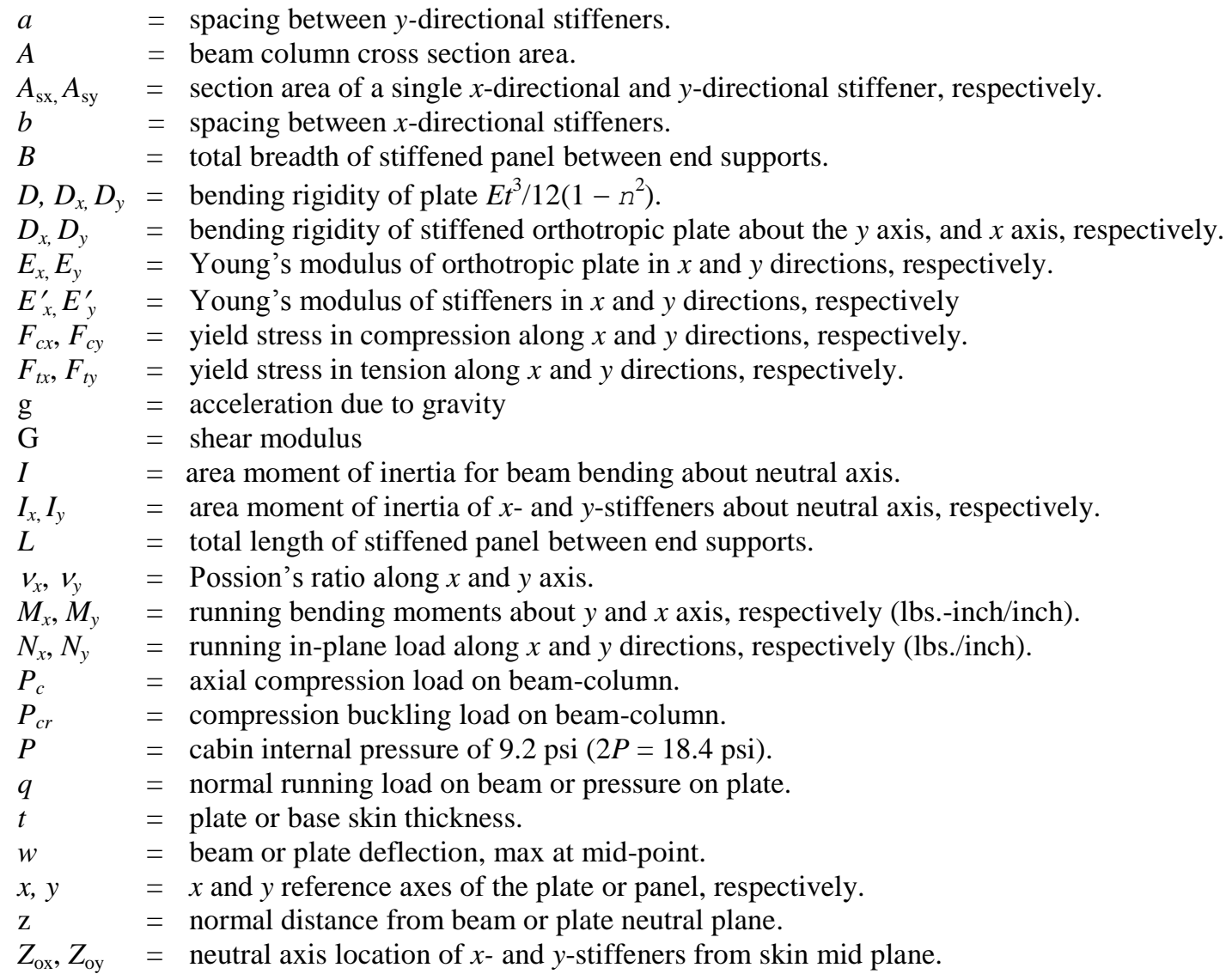

\footnotetext{
${ }^{1}$ Senior Aerospace Engineer, Aeronautical Systems Analysis Branch, MS 442, AIAA Associate Fellow.
} 


\section{Introduction}

A

dvanced composite fuselage configuration development for the Hybrid-Wing-Body ${ }^{1-3}$ (HWB) and Advanced Mobility Concept ${ }^{4}$ flight vehicles are challenging compared to conventional tube and wing airframe technology. The standard stiffened cylindrical fuselage is very efficient, since the skin is mostly under tensile membrane-hoop stress, when pressurized. The streamlined HWB concept is aerodynamically more efficient, however the blended fuselage, with internal rectangular crosssection airframe, is structurally inefficient. The internal cabin pressure combined with flight loads primarily result in highly non-linear bending stresses and large deformations. The bending stresses due to the pressurization are theoretically one order of magnitude higher ${ }^{5}$ than the membrane-hoop stress in a conventional cylindrical fuselage of similar size and skin thickness. Moreover, resulting pillowing effects of the lifting fuselage surface could adversely affect aerodynamic performance advantages provided by the streamlined blended fuselage and wing. Thus, it is necessary to design an efficient fuselage structure in order to reduce the overall structural deflection, and weight penalty, while satisfying the design stress, strain, and buckling safety factors, under the critical design loads. Many structural concepts such as the conventional skin-stringerframe, ribbed-double-shell, multi-bubble stiffened shell, thick sandwich, and Pultruded Rod Stitched Efficient Unitized Structure (PRSEUS ) construction have been studied under NASA HWB research projects ${ }^{5-10}$. Figure 1 shows the finite element model (FEM) development process from a PRSEUS coupon to a 200 passenger HWB vehicle concept, developed at the Boeing Company, Huntington Beach. Preliminary FEM model development, analysis and weight estimation of a conceptual fuselage section and bulkhead configurations were presented in Ref. 11. At the vehicle level, structural systems studies for the 100, 200,300, and 400-passenger versions were presented by Gern ${ }^{12-13}$, to estimate the full vehicle structural weight at critical load conditions. The most recent non-linear analysis of the HWB multi-bay fuselage section was presented by Przekop ${ }^{14}$. This paper presents additional analytical studies of stiffened panels and updated FEM analysis of an integrated fuselage section and bulkhead, with a limited set of critical design loads. Analytical deflection and stresses are obtained with appropriate assumptions for a set of stiffened panel configurations. This analytical parametric study is applied for sizing and case study. An improved FEM of an integrated fuselage section with bulkhead is described. The PRSEUS construct is approximately modeled for the FEM analysis. Stress analysis and scenario based optimization studies are conducted for design improvement. The FEM model specific weight of each of the advanced composite construct is compared to alternative concepts that had been studied previously, in order to assess the relative weight/strength advantages.

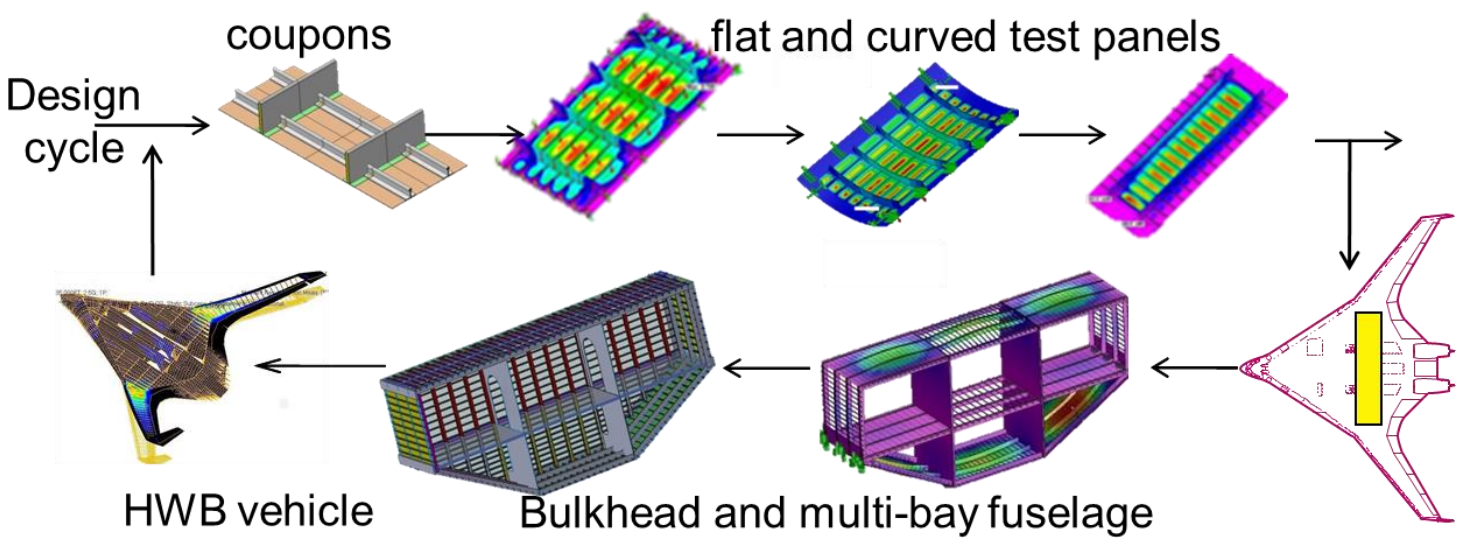

Figure 1. Hybrid-Wing-Body (HWB) PRSEUS FEM model development, analysis and design process.

\section{Classical Stiffened Plate Analysis}

Since the finite element model development of the PRSEUS concept requires many levels of simplification and idealization from the coupon to the fuselage, an analytical model is developed at the panel level for rapid parametric study and sizing. This would also enable one to evaluate the effect of skin thickness, frame and rod-stringer spacing and section geometry on the panel deflection due to a pressure load and for buckling analysis due to in-plane compression load. Classical orthotropic stiffened plate equations ${ }^{15,16}$ are applied to simplify the PRSEUS model analysis for a rectangular plate. These spread-sheet based analytical results are essential for sanity check of the high fidelity FEM analysis of panels, fuselage section and bulkhead. SolidWorks and SolidWorksSim ${ }^{17}$ were used for rapidly building detailed models of the vehicle fuselage sections for structural analysis and design. A large number of design options were considered such as the orthotropic 
skin thickness, frame and rod-stringer geometry and spacing, for obtaining deformation pattern, stress and strain distributions at critical areas. For each configuration, structural weight was computed for weight/strength comparison. Figure 3 shows the stiffened plate configuration with rod-stringer and frame stiffeners. The linear equations for bending of a simply supported bi-axially stiffened plate are shown in Eqs. (1-5). For clamped edge boundary conditions, standard solution tables ${ }^{15-16}$ are utilized to determine maximum deflection, bending moments, stresses and in-plane buckling loads.

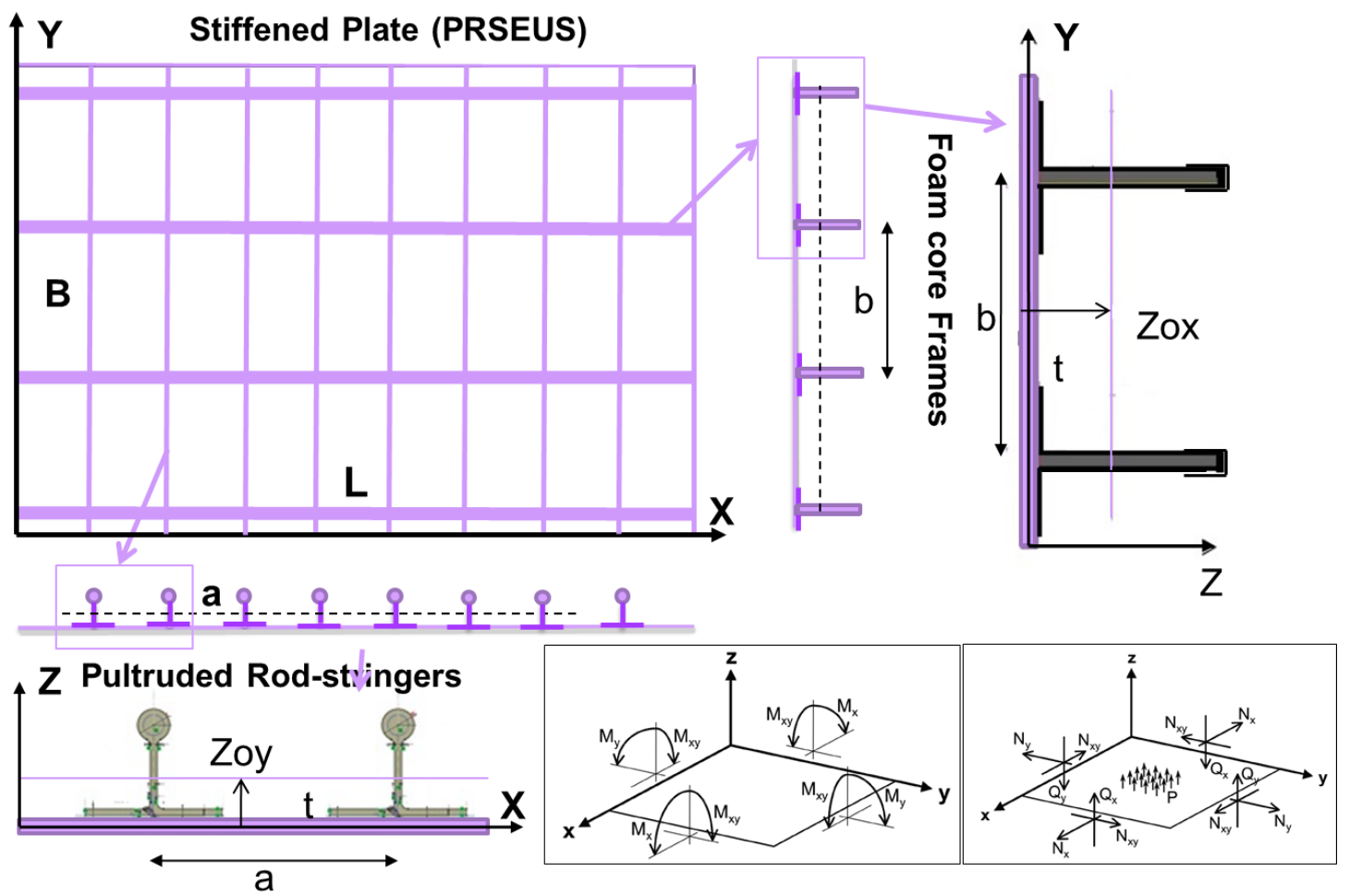

Figure 2. Foam-core frame and pultruded rod-stringer stiffened orthotropic plate configuration.

Plate Bending Analysis: Consider the biaxially stiffened plate shown in Figure 2. For an isotropic thin rectangular plate of uniform thickness $t$, length $L$ and width B, the maximum deflection may be expressed by Eq. 1 which is a function of the pressure load q, plate bending stiffness $D$ and the factor $k$ that is calculated from analytical solution for each boundary condition. The factor $k$ can be presented in tabular form ${ }^{15-16}$, as a function of the ratio $\mathrm{B} / \mathrm{L}$. For example, for a square plate with built-in edges, $k=0.00126$ for $B / L=1$. For a simply supported isotropic square plate, $k=0.00406$.

$$
w_{\max }=k \cdot q \cdot L^{4} / D \text { where } D=E t^{3} / 12\left(1-v^{2}\right)
$$

From ideal orthotropic plate theory ${ }^{15}$, for a simply supported stiffened rectangular plate, a good approximation for maximum deflection is given by

$$
w_{\max }=\frac{16 q}{\pi^{6}} \frac{1}{\left(\frac{D_{x}}{L^{4}}+\frac{2 H}{L^{2} B^{2}}+\frac{D_{y}}{B^{4}}\right)}
$$

The flexural rigidity $\mathrm{D}_{\mathrm{x}}, \mathrm{D}_{\mathrm{y}}$ and $\mathrm{H}$ can be approximately defined by Eqs. (3-5).

$$
\begin{aligned}
& D_{x}=\frac{E_{x} t^{3}}{12\left(1-v_{x} v_{y}\right)}+\frac{E_{x} t Z_{o x}^{2}}{12\left(1-v_{x} v_{y}\right)}+\frac{E_{x}^{\prime} I_{x}}{b} \\
& D_{y}=\frac{E_{y} t^{3}}{12\left(1-v_{x} v_{y}\right)}+\frac{E_{y} t Z_{o y}^{2}}{12\left(1-v_{x} v_{y}\right)}+\frac{E_{y}^{\prime} I_{y}}{a} \\
& H=\sqrt{D_{x}} D_{y}
\end{aligned}
$$


The terms $Z_{o x}, Z_{o y}, a$ and $b$ in Eq.(3-5) are shown in Fig. 2. The equivalent plate rigidity $D_{x}, D_{y}$ resists bending moment $M_{x}$, $M_{y}$ about the $y$ - and $x$ - axis, respectively. The attached longitudinal stiffening frames, each with area $A_{s x}$ and individual bending stiffness $E_{x}^{\prime} I_{x}$ move up the local neutral plane by $Z_{o x}$ from the plate neutral (mid) plane, thereby increasing the total area and the bending rigidity. The notation $E_{x}^{\prime}$ is used to differentiate the stiffener elastic modulus from the plate elastic modulus $E_{x}$. Similarly, the transverse rod-stringers, each with area $A_{s y}$ and bending stiffness $E_{y}^{\prime} I_{y}$, increase the plate flexural rigidity $D_{y}$ by moving up the section-area center by $Z_{o y}$ from the plate neutral plane.

Table 1. Basic Material Properties

\begin{tabular}{|c|c|c|c|c|c|}
\hline \multicolumn{2}{|c|}{ Material symbol } & \multirow{2}{*}{$\begin{array}{l}\text { Property } \\
\text { Elastic modulus }\end{array}$} & \multirow{2}{*}{$x$} & \multirow{2}{*}{\multicolumn{2}{|c|}{$\begin{array}{r}\text { unit } \\
9.75 E+06 \text { psi }\end{array}$}} \\
\hline skin & Ex & & & & \\
\hline & Ey & Elastic modulus & y & $4.86 \mathrm{E}+06$ & psi \\
\hline & Gxy & Shear modulus & & $2.27 \mathrm{E}+06$ & psi \\
\hline & nux & Poisson's ratio & & 0.39 & \\
\hline & nuy & Poisson's ratio & & 0.2 & \\
\hline & rho & density & & 0.057 & $\mathrm{lb} / \mathrm{in}^{\wedge} 3$ \\
\hline & Ftx & allowable stress & tension & 105100 & psi \\
\hline & Fty & allowable stress & tension & 79200 & psi \\
\hline & Fcx & allowable stress & comp & 46500 & psi \\
\hline & Fcy & allowable stress & comp & 37900 & psi \\
\hline \multirow[t]{2}{*}{ rod } & $E^{\prime} y$ & Elastic modulus & & $1.90 \mathrm{E}+07$ & psi \\
\hline & ny & Poisson's ratio & & 0.29 & \\
\hline \multirow[t]{3}{*}{ WF110 } & $E$ & Elastic modulus & & 21000 & psi \\
\hline & G & Shear modulus & & 8250 & \\
\hline & rho & density & & 0.0036 & $\mathrm{lb} / \mathrm{in}^{\wedge} 3$ \\
\hline \multirow[t]{3}{*}{ WF220 } & $E$ & Elastic modulus & & 39150 & psi \\
\hline & G & Shear modulus & & 14500 & psi \\
\hline & rho & density & & 0.0074 & $\mathrm{lb} / \mathrm{in}^{\wedge} 3$ \\
\hline
\end{tabular}
including a $2 \mathrm{in}$. wide cover-strap and base skin between the rod-stringers spaced at 6 inches. For the rod-stringer shown in Table $2 \mathrm{~d}$, with $0.208 \mathrm{in}$. web thickness, $D_{y}=1.43 \times 10^{6} \mathrm{lbs}$. $-\mathrm{in}$. The double wrap rod-stringer configuration is applied in the FEM analysis. These frame-stiffened plate properties are applied to the classical plate bending equations, subject to uniform distributed pressure load of $q$ psi with lamped edge boundary conditions. When the frame spacing or rod-stringer spacing is increased to 24 inches or 8 inches, respectively, the corresponding running bending stiffness is reduced accordingly. Table 2a-d show the corresponding running stiffness with one stack $(0.052 \mathrm{in}$. $)$ or two stacks $(0.104$ in. $)$ base skin thickness. The basic dimensions of the built-up frames and pultruded rod-stringers are shown in the sketch next to each table. Allowable maximum tensile and compressive axial running loads, based on the allowable strain are also shown in the last column.

Simply Supported Stiffened Plate: For a simply supported square plate in Eq. $(1), k=0.00406$. Note that for a square plate, from Eq. (2), $k=4 / \pi^{6}=0.00416$, which is approximately $2.5 \%$ higher than the more accurate value of $k=0.00406$. For an orthotropic plate, one may substitute $\sqrt{ }\left(D_{x} D_{y}\right)$ for D in Eq.(1) to get $w_{\max }=k . q . L^{4} / \sqrt{ }(D x D y)$ with applicable tabular value of $k$, for a given edge boundary condition and $B / L$ ratio. This simple approximation, $w=k . q . L^{4} / \sqrt{ } D_{x} D_{y}$ may provide reasonable average result for maximum deflection of a bi-axially stiffened plate, for appropriate k factor values. For the tabular value of k, see Ref. 15, Figure 91, pp.197, and Table 35, pp. 202. This equation may be viewed as an equivalent orthotropic approximation, which does not distinguish between running direction of frames and rod-stringers in rectangular panels, but accounts for different boundary condition through the $k$ factor. 


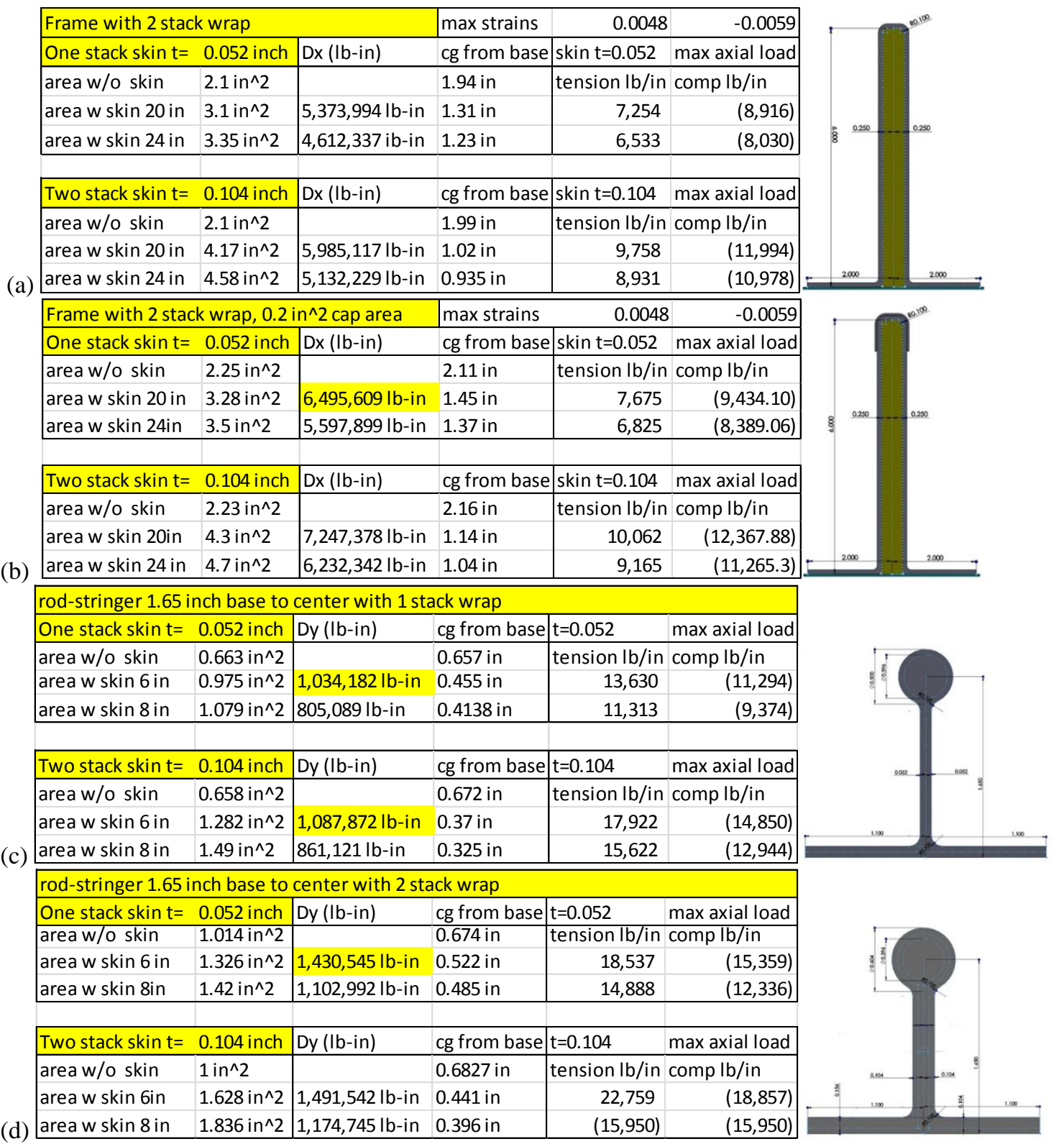

Table $2 \mathrm{a}-2 \mathrm{~d}$. Frames and pultruded rod-stringer section properties with cross-section sketches (not to scale).

Clamped Edge Stiffened Plate: Table 3 shows the maximum deflection of a set of stiffened clamped panels with the frame configuration properties, shown in Table 2b, and rod-stringer, shown in Table 2c, and 18.4 psi pressure load. The plate bending stiffness $D_{x}$ and $D_{y}$ were computed from Eqs. (3-5) with 20 inch or 24 inch frame spacing, 6 inch or 8 inch rodstringer spacing, 0.052 inch or 0.104 inch skin thickness. The last column in the Table 3 shows the equation used for each of the 14 cases. Case 1 is for a frame stiffened $\left(D_{x}\right)$ square plate in both directions $\mathrm{x}$ and $\mathrm{y}$. Case 2 is for rod-stringer stiffened $\left(D_{y}\right)$ square plate in both directions $\mathrm{x}$ and $\mathrm{y}$. In the cases 3 to 6,9 and 10 , stiffness $D$ is replaced by $\sqrt{ }\left(D_{x} . D_{y}\right)$ as an approximate orthotropic approximation, as discussed before. In the case 10, a 90x140 in. stiffened plate (lower bay side-keel panels) this approximation yields a maximum deflection of 1.05 inches. However, these approximations yield a median deflection value that does not distinguish between running direction of frames and rod-stringers in rectangular panels. In cases 11 and $13, D / L^{4}$ in Eq. (1) is replaced by $\left[D_{x} / L^{4}+2 H /\left(L^{2} B^{2}\right)+D_{y} / B^{4}\right] / 4$ with $\mathrm{k}$ factors for the specific $\mathrm{B} / \mathrm{L}$ ratio $(\mathrm{L}<\mathrm{B})$ from Ref. 15. This approximation, shown in Eq. (6) is applied to bi-axially stiffened orthotropic plate. 


$$
w_{\max }=\frac{4 k q}{\left(\frac{D_{x}}{L^{4}}+\frac{2 H}{L^{2} B^{2}}+\frac{D_{y}}{B^{4}}\right)}
$$

In the case 6 , for an $80 x 120$ inch panel, the plate maximum deflection is approximately 0.64 inches. In case 11 , the stiffener frames $\left(D_{x}>D_{y}\right)$ are running along shorter direction $L$ and the maximum deflection is 0.74 inches for an $80 x 120 \mathrm{in}$. panel, with 20 inch frame spacing and 6 in. rod-stringer spacing. In the case $12, \mathrm{D} / \mathrm{L}^{4}$ in Eq. (1) is replaced by $\left[D_{y} / L^{4}+2 H /\left(L^{2} B^{2}\right)+D_{x} / B^{4}\right] / 4$, (Interchange $D_{x}$ with $D_{y}$ ) which represents stiffer frames $\left(D_{x}\right)$ running along the longer direction $B$. In this case the maximum deflection is 1.44 inches. These spread sheet based calculations were used for weight and configuration case study as well as for sanity check of numerical finite element results. Cases 6,13 and 14 show results from these three deflection equations for the 90x140 in. stiffened panel.

Table 3. Clamped edge stiffened plate maximum deflection due to uniform normal pressure load of 18.4 psi, for a set of frame spacing ( $f s p=20$ or $24 \mathrm{in}$.), rod-stringer spacing ( $r s p=6$ or $8 \mathrm{in}$.) and skin thickness $(t=0.052$ or $0.104 \mathrm{in}$.).

\begin{tabular}{|c|c|c|c|c|c|c|c|c|c|c|c|c|c|c|}
\hline \multicolumn{9}{|c|}{ Uniformly loaded Clamped stiffened plate: Table 35, p202, Fig. 91 p197 Timoshenko } & & & fsp & 0 & ssp & 6 \\
\hline \multicolumn{4}{|c|}{ rod-stringer rod center distance (in) } & \multicolumn{2}{|l|}{1.65} & 1.65 & webt & 0.104 & rod dia & 0.479 & $\operatorname{skint}$ & 0.0 & stra & 0.104 \\
\hline \multirow[t]{3}{*}{ CASE } & $q(p s i)$ & 18.4 & fsp 24 & 20 & 24 & 20 & fsp 24 & 20 & 24 & 20 & \multicolumn{4}{|c|}{ fsp - frame spacing } \\
\hline & length & width & $\operatorname{rsp} 8$ & 8 & 6 & 6 & rsp 8 & 8 & 6 & 6 & \multicolumn{4}{|c|}{ rsp - rod stringer spacing } \\
\hline & $\mathrm{L}$ & B & $t=0.052$ & $t=0.052$ & $t=0.052$ & $t=0.052$ & $t=0.104$ & $t=0.104$ & $\mathrm{t}=0.104$ & $\mathrm{t}=0.104$ & \multicolumn{4}{|c|}{ t skin thickness } \\
\hline NO & \multirow{2}{*}{\multicolumn{2}{|c|}{$\frac{(\mathrm{L}<\mathrm{B})}{120}$}} & & & & & & & & & & $\max d$ & flectio & uation \\
\hline 1 & & & 0.86 & 0.74 & 0.86 & 0.74 & 0.77 & 0.66 & 0.77 & 0.66 & \multicolumn{4}{|c|}{ wmax $=k q L^{\wedge} 4 / D x, L=B$} \\
\hline 2 & 90 & 90 & 1.89 & 1.89 & 1.47 & 1.47 & 1.77 & 1.77 & 1.40 & 1.40 & \multicolumn{4}{|c|}{$w \max =\mathrm{kqB}^{\wedge} 4 / \mathrm{Dy}, \mathrm{L}=\mathrm{B}$} \\
\hline 3 & 104 & 104 & 1.28 & 1.18 & 1.13 & 1.04 & 1.17 & 1.08 & 1.04 & 0.96 & \multicolumn{4}{|c|}{ wmax $=k . q .\left(L^{\wedge} 4\right) / \operatorname{sqrt}\left(D x^{*}\right.$ Dy), L=B } \\
\hline 4 & 90 & 117 & 1.09 & 1.01 & 0.96 & 0.89 & 1.00 & 0.92 & 0.89 & 0.82 & \multicolumn{4}{|c|}{ wmax=k.q.(L^4)/sqrt(Dx.Dy), B/L=1.3 } \\
\hline 5 & 90 & 120 & 1.12 & 1.03 & 0.98 & 0.91 & 1.02 & 0.95 & 0.91 & 0.84 & \multicolumn{4}{|c|}{ wmax =k.q.(L^4)/sqrt(Dx.Dy), B/L=1.33 } \\
\hline 6 & 80 & 120 & 0.78 & 0.73 & 0.69 & 0.64 & 0.72 & 0.66 & 0.64 & 0.59 & \multicolumn{4}{|c|}{ wmax=k.q.(L^4)/sqrt(Dx.Dy), B/L=1.5 } \\
\hline 7 & 60 & 120 & 0.11 & 0.09 & 0.11 & 0.09 & 0.10 & 0.08 & 0.10 & 0.08 & \multicolumn{4}{|c|}{ wmax $=k q L^{\wedge} 4 / D x, \quad B=2 L \quad B / L=2$} \\
\hline 8 & 90 & 180 & 3.81 & 3.81 & 2.96 & 2.96 & 3.56 & 3.56 & 2.82 & 2.82 & \multicolumn{4}{|c|}{ wmax $=k q L^{\wedge} 4 / D y, \quad B=2 L \quad B / L=2$} \\
\hline 9 & 90 & 180 & 1.45 & 1.34 & 1.28 & 1.18 & 1.32 & 1.23 & 1.18 & 1.09 & \multicolumn{4}{|c|}{ wmax=k.q.(L^4)/sqrt(Dx.Dy), B=2L } \\
\hline 10 & 90 & 140 & 1.28 & 1.19 & 1.13 & 1.05 & 1.17 & 1.09 & 1.04 & 0.97 & \multicolumn{4}{|c|}{ wmax $=$ k.q. $\left(L^{\wedge} 4\right) /$ sqrt(Dx.Dy), B $=1.55 \mathrm{~L}$} \\
\hline \multirow[t]{2}{*}{11} & 80 & 120 & 0.87 & 0.76 & 0.84 & 0.74 & 0.78 & 0.69 & 0.76 & 0.67 & \multicolumn{4}{|c|}{$\operatorname{wmax}=4^{*} k \cdot q /\left[\mathrm{Dx} / \mathrm{L}^{\wedge} 4+2 \mathrm{H} /\left(\mathrm{L}^{\wedge} 2 \cdot \mathrm{B}^{\wedge} 2\right)+\mathrm{Dy} / \mathrm{B}^{\wedge} 4\right]$} \\
\hline & & & & & & & & & & & \multicolumn{4}{|c|}{$\mathrm{B} / \mathrm{L}=1.5(\mathrm{~L}<\mathrm{B})$ switch $\mathrm{Dx}$ and $\mathrm{Dy}$} \\
\hline 12 & 80 & 120 & 1.75 & 1.61 & 1.55 & 1.44 & 1.60 & 1.47 & 1.43 & 1.32 & \multirow{2}{*}{\multicolumn{4}{|c|}{ wmax $=4^{*} \mathrm{k} \cdot \mathrm{q} /\left[\mathrm{Dy} / \mathrm{L}^{\wedge} 4+2 \mathrm{H} /\left(\mathrm{L}^{\wedge} 2 \cdot \mathrm{B}^{\wedge} 2\right)+\mathrm{Dx} / \mathrm{B}^{\wedge} 4\right]$}} \\
\hline 13 & 90 & 140 & 1.45 & 1.27 & 1.40 & 1.23 & 1.31 & 1.15 & 1.27 & 1.11 & & & & \\
\hline & & & & & & & & 2. & & & \multicolumn{4}{|c|}{$\mathrm{B} / \mathrm{L}=1.555(\mathrm{~L}<\mathrm{B})$ switch Dx and Dy } \\
\hline 14 & 90 & 140 & 3.09 & 2.85 & 2.73 & 2.53 & 2.83 & 2.61 & 2.52 & 2.34 & \multicolumn{4}{|c|}{ wmax $=4 * k . q /\left[D y / L^{\wedge} 4+2 H /\left(L^{\wedge} 2 \cdot B^{\wedge} 2\right)+D x / B^{\wedge} 4\right]$} \\
\hline \multicolumn{3}{|c|}{ specific weight $\mathrm{Ib} / \mathrm{ft}^{\wedge} 2$} & 1.94 & 2.11 & 2.17 & 2.33 & 2.36 & 2.52 & 2.58 & 2.75 & \multicolumn{4}{|c|}{ Unit weight estimate $\mathrm{Ib} / \mathrm{ft}^{\wedge} 2$} \\
\hline
\end{tabular}

Table 4. Maximum deflection and stress result summary of a 90x140 in. PRSEUS stiffened panel with skin thicknesses 0.052 and $0.104 \mathrm{in}$., capped frame (Table 2b) spacing of 20 or 24 in., rod-stringer (Table 2d) spacing of 6 or 8 in., with 18.4 psi normal pressure load.

\begin{tabular}{|c|c|c|c|c|c|c|c|c|c|c|c|c|}
\hline \multicolumn{4}{|c|}{ Clamped Stiffened Plate (Timoshenko) } & Rod b2c & 1.65 & webt t & 0.104 & rod dia & 0.479 & frame wrap t 0.104 & strap t & 0.104 \\
\hline$q(p s i)$ & 18.4 & fsp 24 & 20 & 24 & 20 & fsp 24 & 20 & 24 & 20 & \multicolumn{3}{|c|}{ fsp - frame spacing } \\
\hline \multirow{2}{*}{$\begin{array}{l}\text { length } \\
L(L<B)\end{array}$} & width & & 8 & 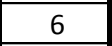 & 6 & $\operatorname{rsp} 8$ & 8 & 6 & 6 & \multicolumn{3}{|c|}{ rsp - rod stringer spacing } \\
\hline & B & 4 & $t=0.052$ & $t=0.052$ & $t=0.052$ & $t=0.104$ & $t=0.104$ & $t=0.104$ & $t=0.104$ & $\mathrm{t}$ is base skin thicknes & $s \mathrm{~s}$ (inch) & \\
\hline \multicolumn{2}{|c|}{ str weight $\mathrm{lb} / \mathrm{ft}^{\wedge} 2$} & & & 17 & 2.33 & 2.36 & 2.52 & & & \multirow{2}{*}{\multicolumn{3}{|c|}{$\frac{\text { unit specific weight } \mathrm{lb} / \mathrm{ft}^{\wedge} 2}{\max \text { deflection equation }}$}} \\
\hline $\mathrm{L}$ & B & & & \multicolumn{5}{|c|}{ max deflection at mid point (inch) } & & & & \\
\hline 9 & 14 & & & & 105 & 1.17 & 1.09 & 1. & 0.97 & \multicolumn{3}{|c|}{ wmax $=k . q .\left(L^{\wedge} 4\right) /$ sqrt(Dx.Dy), k=0.00225 } \\
\hline 9 & 14 & & & 1.40 & 1.23 & 1.31 & 1.1 & 1. & 1.11 & \multicolumn{3}{|c|}{ wmax $=4^{*} \mathrm{k} \cdot \mathrm{q} /\left[\mathrm{Dx} / \mathrm{L}^{\wedge} 4+2 \mathrm{H} /\left(\mathrm{L}^{\wedge} 2 \cdot \mathrm{B}^{\wedge} 2\right)+\mathrm{Dy} / \mathrm{B}^{\wedge} 4\right]$} \\
\hline 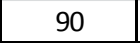 & 1 & & & 2.73 & 2.53 & 2.83 & 2.61 & 2.52 & 2.34 & \multicolumn{3}{|c|}{ wmax $=4^{*} k \cdot q /\left[D y / L^{\wedge} 4+2 H /\left(L^{\wedge} 2 \cdot B^{\wedge} 2\right)+D x / B^{\wedge} 4\right]$} \\
\hline$M x(L / 2,0)$ & -11450 & 00 & -68800 & -80000 & -68800 & -71800 & -61600 & -71800 & -61600 & \multirow{2}{*}{\multicolumn{2}{|c|}{$\begin{array}{l}\max \text { stress Mx.4/Ix } \\
\text { max stress My. } 1 / \text { ly }\end{array}$}} & \\
\hline $\mathrm{My}(0, \mathrm{~B} / 2)$ & -8500 & -51400 & -51400 & -40000 & -40000 & -48000 & -48000 & -38000 & -38000 & & & \\
\hline $\mathrm{x}(\mathrm{mid})$ & 5580 & & 33500 & 39000 & 33500 & 35000 & 30000 & 35000 & 30000 & \multirow{2}{*}{\multicolumn{2}{|c|}{$\begin{array}{l}\max \text { stress Mx.4/Ix } \\
\max \text { stress My.1/ly }\end{array}$}} & \\
\hline$y$ y(mid) & 2950 & 17800 & 7800 & 13900 & 13900 & 16700 & 16700 & 13200 & 13200 & & & \\
\hline
\end{tabular}


Table 4 shows the specific weight, deflections and estimated local maximum stress values of a 90x140 in. PRSEUS stiffened panel. Rows 2 to 4 show the set of frame spacing, rod-stringer spacing and skin thickness, which result in increasing order of specific weight/unit pressurized surface area (row 4). The corresponding maximum deflections and bending stresses due to the bending moments in the $\mathrm{x}$ and $\mathrm{y}$ directions at the mid-edge and center of the plate are also shown. The maximum stress values are computed from the bending moment at mid-edge and center of the plate at the top of the capped frames and rod-stringers. Pressure load is positive in the $\mathrm{Z}$ direction normal to the clamped panel. Hence, the maximum stresses are in compression on the panel clamped-edge at the top of the frames. The bending stresses at mid-panel are in tension. This scenario is similar to the loading condition on the bulkhead where frames and rod-stringers are located on the outer side of the pressurized cabin. However, if internal cabin-pressure acts in the negative $\mathrm{Z}$ direction, like on the multi-bay cabin panels, where frames and rod-stringers are built inside the fuselage, the stress situation may be reversed. The maximum stresses are in tension on the panel clamped-edges at the top of the frames. The maximum bending stresses at the mid-panel are in compression. The maximum stresses may locally exceed allowable compression stresses for the 18.4 psi pressure load. For the 9.2 psi operational cabin pressure, the maximum stresses are within the allowable limits. Possible optimal combinations are outlined in the Table 4. These two selections are; (a) 20 inch frame spacing, 6 inch rod-stringer spacing with 1 stack skin, and (b) 24 inch frame spacing, 8 inch rod-stringer spacing with two stack skin. The case (b) is preferable due to better damage tolerance, although the maximum deflection and specific weight is slightly higher for this case compared to that of case (a). The maximum stresses are also higher in case (b).

Simply Supported Panel Buckling: Consider the simply supported stiffened plate in Fig. 2 under normal loading q and in-plane compressive running load $\mathrm{N}_{\mathrm{x}}$, then the solution for deformation can be expressed approximately by

$$
w_{\max }=\frac{16 q}{\pi^{6}} \frac{1}{\left(\frac{D_{x}}{L^{4}}+\frac{2 H}{L^{2} B^{2}}+\frac{D_{y}}{B^{4}}-\frac{N_{x}}{\pi^{2} L^{2}}\right)}
$$

The value of the in-plane compressive running load $N_{x}$ that renders the denominator of Eq. (7) to zero will provide the inplane buckling running load. Hence, the in-plane critical compressive buckling load $N_{x c r}$ for the simply supported edge condition is given by

$$
N_{x c r}=\pi^{2} L^{2}\left[D_{x} / L^{4}+2 * H /\left(L^{2} \cdot B^{2}\right)+D_{y} / B^{4}\right] .
$$

For the orthotropic rectangular plate with $L=120 \mathrm{in}$., $B=90 \mathrm{in}$., $D_{x}=6.5 \times 10^{6} \mathrm{lb}$-in and $D_{y}=1.03 \times 10^{6} \mathrm{lb}$-in, the critical inplane running load $N_{x c r}$ is $11,800 \mathrm{lbs}$./in. For an isotropic square plate, the critical minimum buckling is given by $N_{x c r}=$ $4 \pi^{2} D / L^{2}$. For a $104 \times 104 \mathrm{in}$. square simply supported plate with $D$ replaced by $\sqrt{ }\left(D_{x} D_{y}\right), N_{x c r}=8700 \mathrm{lbs} . / \mathrm{in}$.

\section{Integrated Multi-bay and Bulkhead Analysis.}

A typical multi-bay and bulkhead FEM models were analyzed individually in Ref. 11. Based on the lesson learned, an improved FEM model of an integrated multi-bay and bulkhead was developed. This configuration, shown in Fig. 3, was studied for several purposes, namely; 1) Explore the effect of different modeling techniques and configurations; 2) Determine an equivalent plate thickness to represent the bulkhead and passenger-floor for 18.4 psi pressure load; and 3) Capture the critical area behavior with asymmetric bending-torsion loads. The equivalent plate representation may be utilized for building simplified full vehicle FEM model. The passenger floor and rear bulkhead were modeled as unstiffened uniform shell with 1 inch and 1.5 inch equivalent thicknesses, respectively. In Fig. 3, the rear bulkhead is hidden in order to show the interior details. The equivalent thicknesses were selected to provide same order of deflection on both bulkheads (stiffened thin shell and uniform shell). This mixed model is 6 inches shorter on both ends than the multi-bay analyzed previously ${ }^{11}$. The three crown panel frames are at 24 inches spacing and have 2 stacks wrap (Table 2a). The rod-stringer are at 8 inches spacing on crown panels, keel panels, outer rib-panels and on forward bulkhead. All rod-stringers have one stack wrap (Table 2c), except for the rod-stringers on crown panel, which have two stacks wrap (Table 2d). The forward bulkhead vertical frames are at 20 inch spacing. Two 0.5 inch thick $\mathrm{L}$ beams were added along the passenger floor edges. This model also included 0.5 inch thick composite core T-beams along the edges for connecting the two bulkheads. The corner braces at the inner-rib panels, keel beams and intercostal supports on the three lower keel bays were not modeled.

The following critical design load conditions were studied for the integrated multi-bay and bulkhead.

Load case 1. 18.4-psi internal static over-pressure at ground level (2P case). 
Load case 2. $2.5 \mathrm{~g}$ climb condition with the cabin operational pressure of $9.2 \mathrm{psi}(1 \mathrm{P}+2.5 \mathrm{~g}$ case $)$

Load case 3. $-1 \mathrm{~g}$ dive condition with the cabin operational pressure of 9.2 psi (1P-1g case)

Load case 4. Buckling analysis at load cases 2 and 3 with additional asymmetric torsion load.

The maximum aerodynamic load for the $1 P+2.5 \mathrm{~g}$ case also produces a maximum compression load on the fuselage crown panels and a maximum tensile load on the fuselage keel panels. This bending load is idealized as approximately 5000-lb/in. running compression and tension load along the top and bottom panels, respectively. This in-plane ultimate design load was derived from full-vehicle FEM analysis ${ }^{8,9,14}$. In this linear analysis, the maximum allowable strain is 0.007 in tension and 0.0058 in compression on the stringer bulb areas. For the orthotropic skin and frame wraps, the allowable maximum strains are assumed to be 0.0059 in tension and 0.0048 in compression.

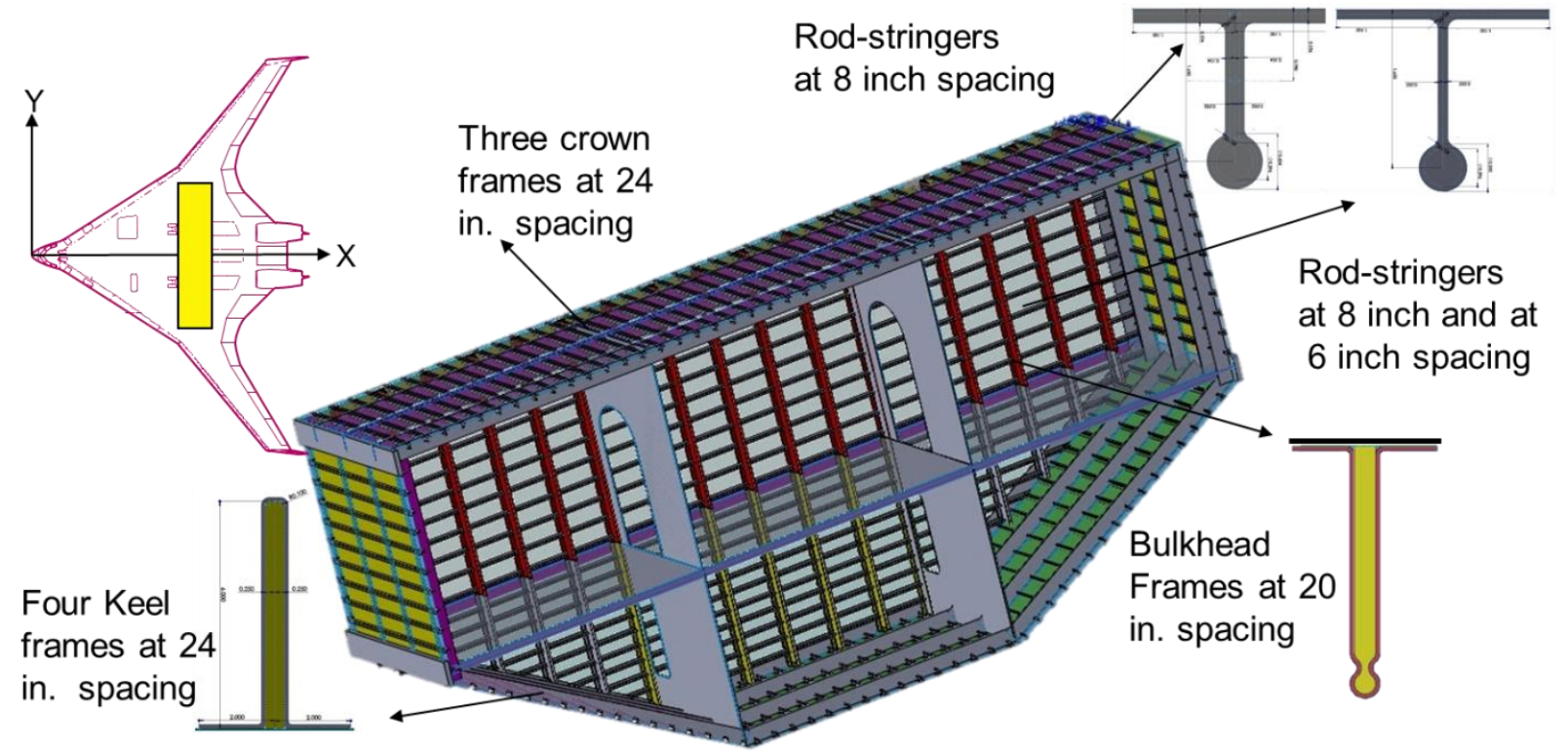

Figure 3. Integrated multi-bay and bulkhead mixed model configuration.

Figure 4 shows the displacements and first principal strain distribution with 18.4 psi internal cabin pressure.

The maximum deflection with 18.4 psi overpressure with one-stack skin has significantly higher local deflections between rod-stringers, which may a cause for local failure and large strains. However, this situation is alleviated with two stack crown surface skin as shown in Fig. 6 shows displacement pattern with two-stack skin on the crown surface with 18.4 psi overpressure. With the two stack skin on crown surface, the maximum deflection is approximately 1.3 inches. This deflection is consistent with the analytical results of an ideal stiffened plate presented in the Tables 3 and 4 in Section II.

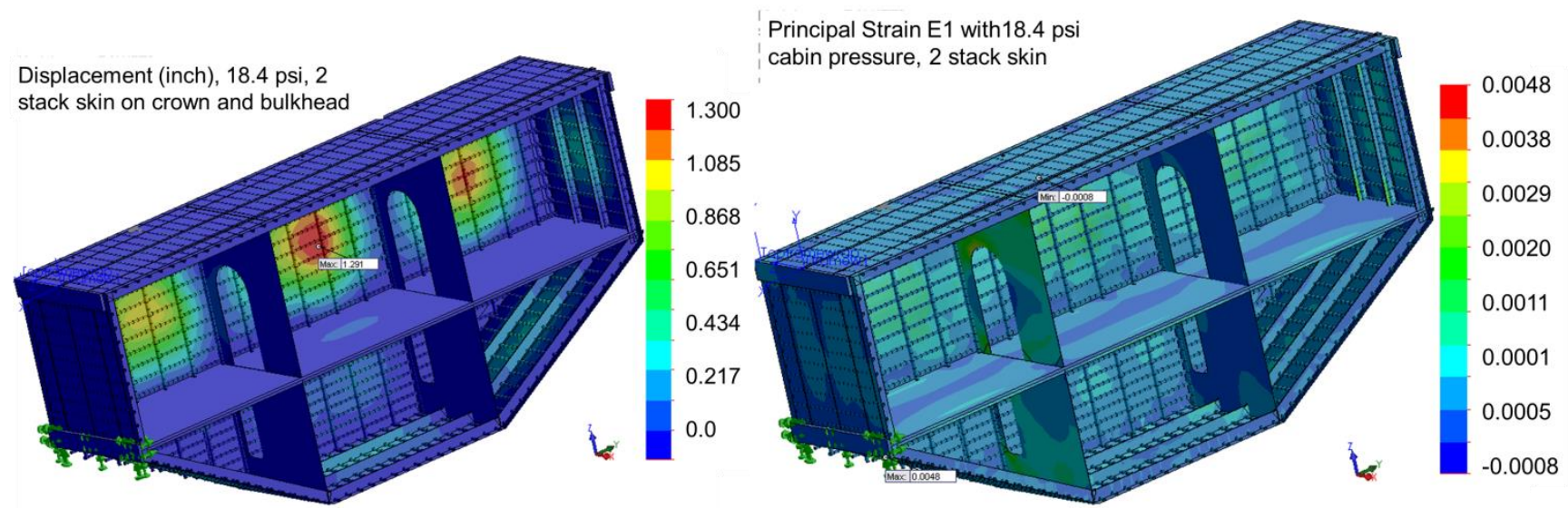

Figure 4. Displacement and first principal strain distribution for the load case 1 with 18.4 psi internal cabin pressure (two stack skins). 
Figure 5 show the displacement and principal strain distribution with 9.2 psi operating cabin pressure, combined with end bending moment and torsion moment. The end-bending moment is determined by the in-plane compression load of 5000 $\mathrm{lbs}$./in. along the crown panel multiplied with $80 \mathrm{inch}$ width of the panel (400,000 lbs.) and the corresponding in-plane tensile load on the passenger floor or wing attachment point. The moment arm of 90 inch creates a total end bending moment of 400,000x90 lb.-in. An asymmetric end-torsion load of $10000 \times 90 \mathrm{lb}$.-in is also applied. For the 2 stack (0.104 inch) skin case, the maximum deflection is 0.35 inches and the first principal strain E1 distributions are within the allowable limits.

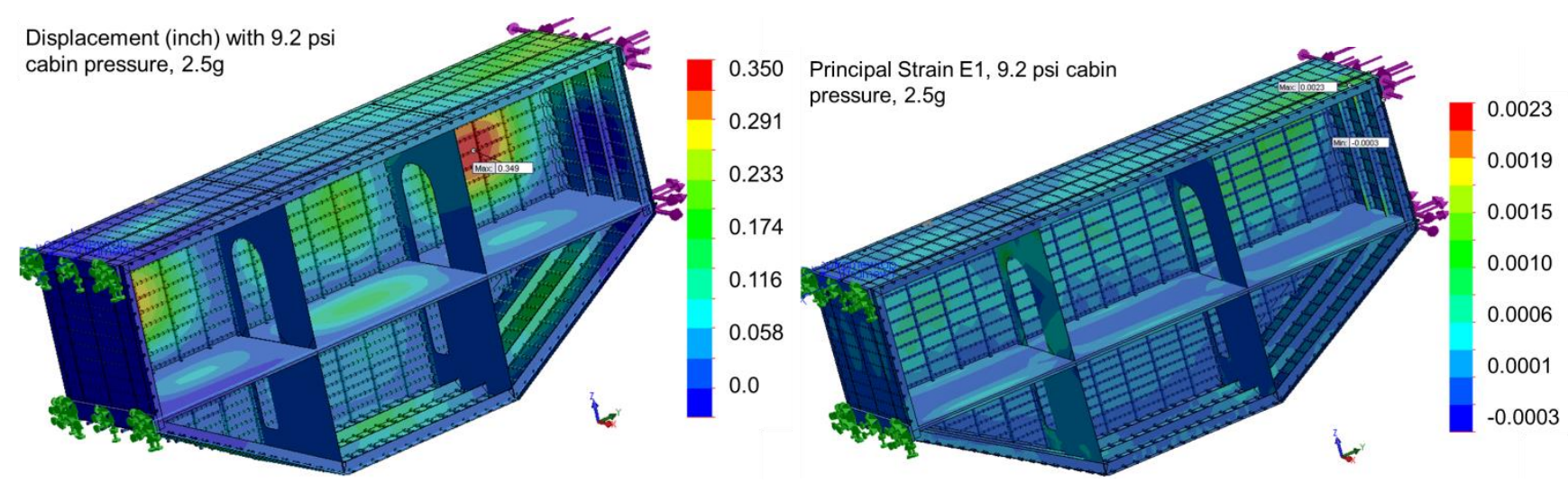

Figure 5. Displacement and first principal strain distribution for load case 2 with 9.2 psi cabin pressure, $400000 \times 90 \mathrm{lbs}$. -in end bending moment and 10000x90 lbs.-in end torsion moment (two stack skins).

The buckling analysis with the load case 4 was conducted for the integrated multi-bay with 24 inch frame spacing and 8 inch rod-stringer spacing. Multiple symmetric and asymmetric local buckling modes with multiple positive and negative buckling factors below unity were identified, although the plate buckling analysis indicated that the in-plane buckling loads are above $5000 \mathrm{lbs}$./inch. Hence two stacks of skin on the crown surface may be necessary to prevent this type of local buckling for this higher spacing of the frame and rod-stringer.

\section{FEM Weight Analysis and Comparison}

The weight analysis and comparison of the several previous and current redesigned feasible configurations are summarized next. In these previous studies, four HWB structural concepts were studied ${ }^{4}$, namely, Vaulted Ribbed Shell (VLRS), Flat Ribbed Shell (FRS); Vaulted shell with Light and Heavy Honeycomb Core (VLHC \& VHHC); and Flat sandwich shell with Light and Heavy Honeycomb Core (FLHC \& FHHC). Multi-bubble section concepts were also analyzed and relative comparisons of component FEM weight breakdown per unit surface area were presented in Refs. 10 and 11. Conventional cylindrical and A380 type elliptic section and stress balanced multi-bubble fuselage sections with frame-ribs and rod-stringers stiffened aluminum skin with 0.118 inch $(3 \mathrm{~mm})$ shell thickness were also analyzed for comparison. The present PRSEUS construction concept designs have lower specific weight than the sandwich and multi-bubble concepts. However, the cylindrical fuselage specific weight is still lower than the specific weight of the present concept. The weight analysis summary of the redesigned multi-bay described in Figs. 3-5, is presented in Table 5. The comparative bar charts of the multi-bay (without bulkhead) and bulkhead were analyzed in Refs, 10, 11. Note that with two stack skin and rodstringers (shown in Table 2d) on the crown surface and bulkhead panels, and with the higher density foam-core, the present design is heavier than previous designs reported in Ref. 11. See Figure 6 for the bar chart comparison of conceptual FEM configuration weights per unit surface area for (a) multi-bay and (b) bulkhead. The total weights are estimated at 2184 lbs. (2.47 lbs./sq. ft.) for the isolated Multibay without the bulkhead and $930 \mathrm{lbs}$. (2.74 lbs./sq. ft.) for a single bulkhead, respectively. With this improved design, the maximum stresses and strains on the composite structure are within the allowable limits. In the previously reported multi-bay ${ }^{11}$ configuration, estimated specific weights were slightly lower, but the stresses and deflections were higher and maximum values at joints, rod-stringers and frames exceeded allowable limits under the 18.4 psi over-pressure load condition. 
Table 5. Weight analysis summary of the integrated multi-bay (without pressure bulkhead).

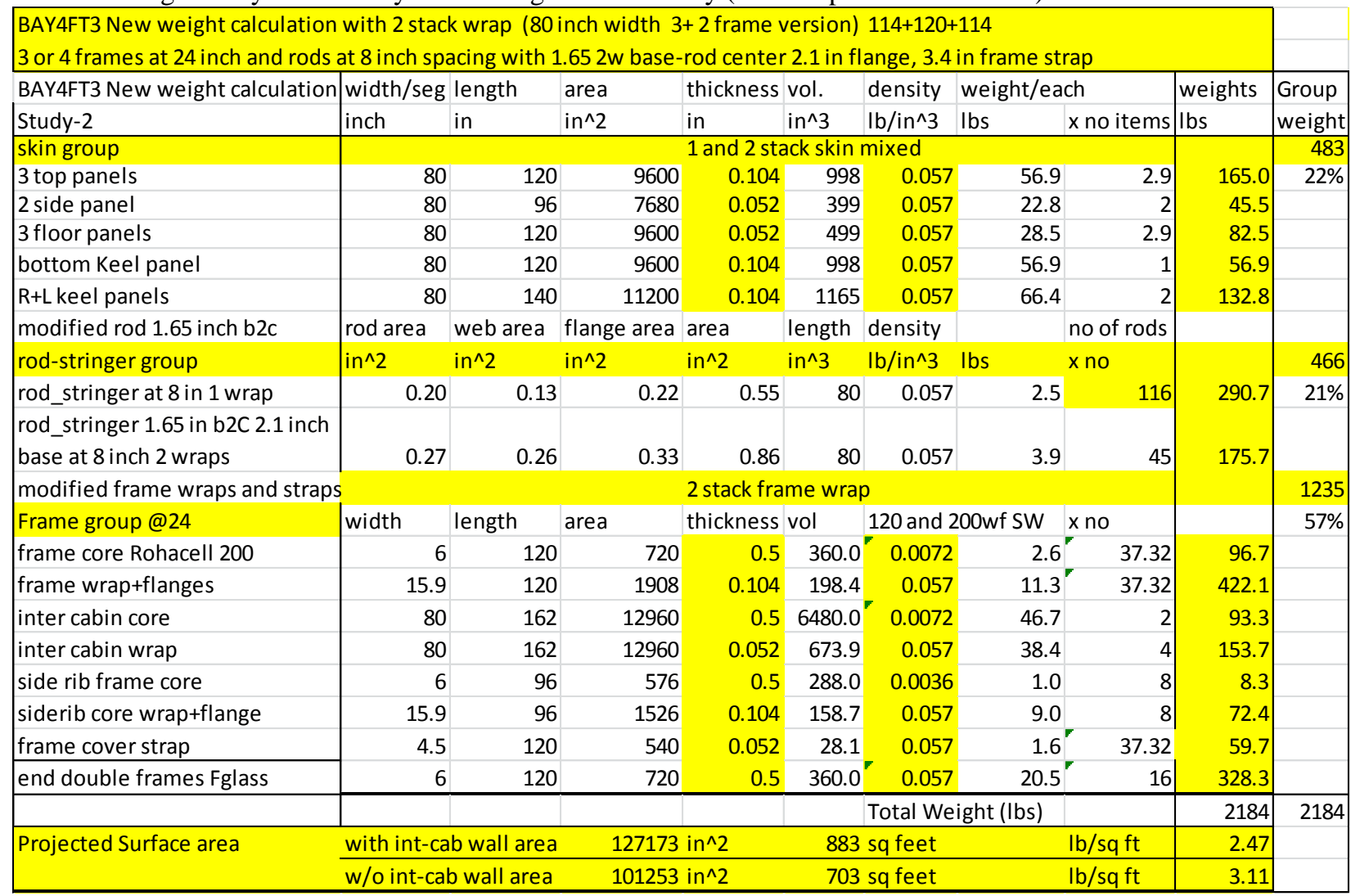

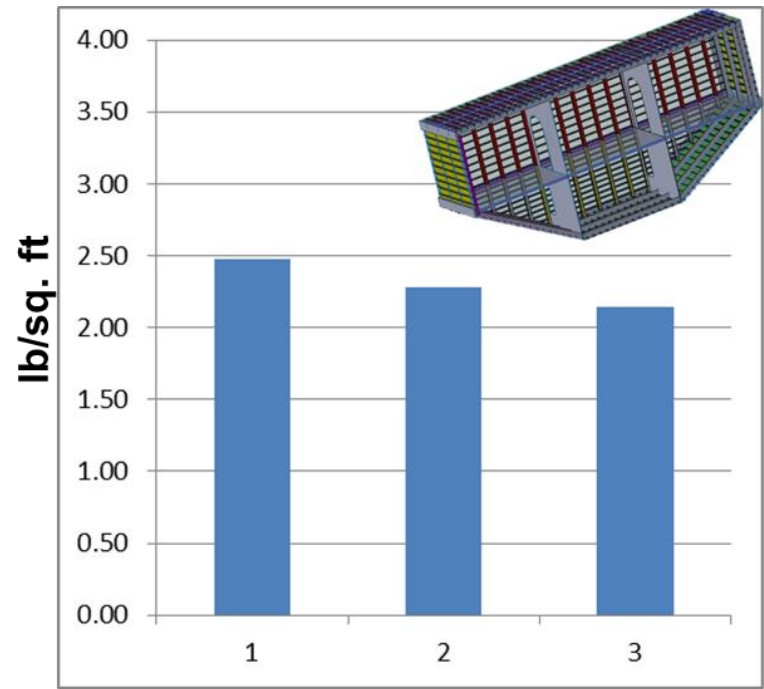

1. 2 stack skin 2 stack wrap rod @6, 4/5 frames at 24

2. 2 stack skin 2 stack wrap rods @6, 4 frames at 24

(a)

3. 2 stack skin 2 stack wrap rods @8, 4 frames at 24

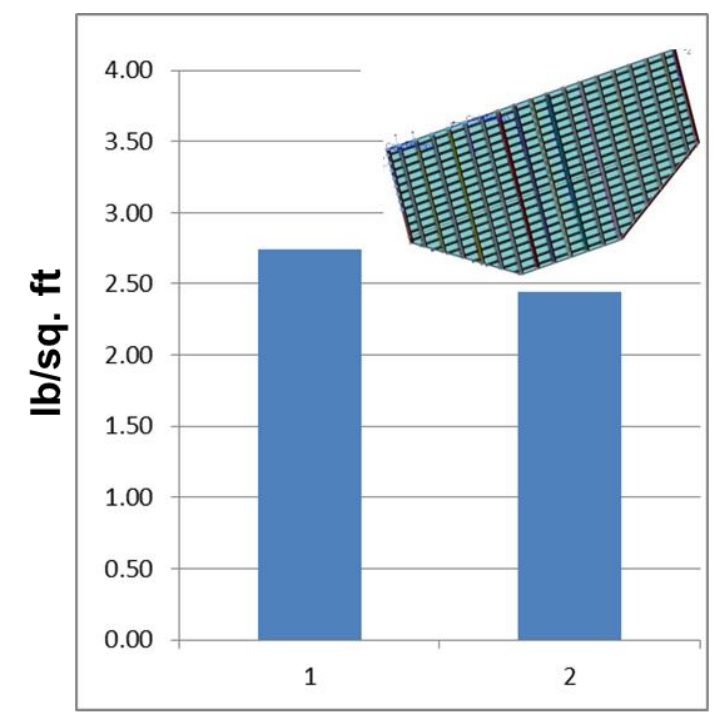

1. 2 stack skin, 2 stack wrap rod@8, frames@20 (b)

Figure 6. Relative conceptual FEM configuration weights per unit surface area for (a) multi-bay and (b) bulkhead.

\section{Conclusions}

Based on lessons learned from previous studies of the Hybrid-Wing- Body vehicle, an improved finite-element model is developed for an advanced composite integrated multi-bay fuselage. An analytical study is presented for structural analysis 
of a composite stiffened panel under 18.4 psi normal pressure. A rational case study is performed to determine the effect of feasible skin-thickness, rod-stringer spacing and frame spacing options on the maximum deflection, stress levels and structural weight and to improve the overall design. A set of critical design load conditions are examined. From the analysis of a multi-bay finite element model, it is concluded that two stack skin laminates will be necessary to improve overall safety margins and impact damage resistance. Two-stack skin would allow slightly higher stiffener spacing of 8 inches to minimize the weight penalty. Two-stack frame-wraps with additional frame caps are recommended to reduce the local strain levels. In addition, reinforced two-stack wrap rod-stringers on the crown surface are applied to reduce the stress level at the $18.4 \mathrm{psi}$ over-pressure condition. Although, local buckling concerns remain at the maximum climb load conditions, the stitched composite structure can carry load in the post buckling condition. The adverse aerodynamic effects due the outer-surface pillowing at operational cabin pressure still remain a concern and need to be analyzed. Analysis of the composite bi-axially stiffened shell concept demonstrated that the hybrid-wing-body class of vehicles can be structurally as efficient as the conventional cylindrical skin-stringer-frame construction. However, alternate concepts such as foam-core hat-stringer should also be considered to address the manufacturing and repair issues. With continuing development, the advanced composite technology has the potential to render the current hybrid-wing-body concept both structurally feasible and aerodynamically efficient.

\section{Acknowledgments}

This research was sponsored by the NASA Environmentally Responsible Aviation (ERA) Project in collboration with the Boeing Company, Huntington Beach. The author wishes to thank Dr. Fayette Collier, Project Manager, ERA Project; Dr. Anthony Washburn, Project Engineer; Pamela Davis, Assoc. Project Manager, Airframe Technology, William Kimmel, Chief Technologist, Systems Analysis and Concepts Directorate, Dr. Mike Marcolini, Branch Head, and Dr. Frank Gern, Assistant Branch Head (Acting), Aeronautical Systems Analysis Branch; as well as the Aeronautics Research Mission Directorate for funding this project. Technical discussion and guidance from Alex Velicki, Dawn Jegley, Craig Nickol and Andrew Lovejoy are greatly appreciated.

\section{References}

1 Liebeck, R. H., Page, M. A., and Rawdon, B. K., "Blended-Wing-Body Subsonic Commercial Transport,” AIAA Paper 1998-0438, January 1998.

${ }^{2}$ Mukhopadhyay, V., "Structural Concepts Study of Non-circular Fuselage Configurations," Paper No. AIAA SAE WAC-67, World Aviation Congress, Los Angeles, Calif. Oct. 22-24, 1996.

${ }^{3}$ Liebeck, R. H, "Design of the Blended Wing Body Subsonic Transport," Journal of Aircraft, Vol. 41, No. 1, Jan-Feb. 2004, pp. 10-25.

${ }^{4}$ Hoffman, K., "Air Vehicle Technology Integration Program (AVTIP), Multi-role Bomber Structural Analysis, AFRL-VAWP-TR-2006-3067, May 2006, Final Report for 14 December 2004-May 2006, AFRL-VA-WP-TR-2006-3067.

${ }^{5}$ Mukhopadhyay, V., Sobieszczanski-Sobieski, J., Kosaka, I., Quinn, G., and Vanderplaats, G., "Analysis, Design and Optimization of Non-cylindrical Fuselage for Blended-Wing-Body Vehicle," Journal of Aircraft, Vol. 41, No. 4, JulyAugust, 2004, pp. 925-930.

6 Velicki, A., and Thrash, P. J., “Advanced Structural Concept Development Using Stitched Composites," The Boeing Company, Huntington Beach, California 92647-2099, AIAA Paper 2008-2329.

${ }^{7}$ Velicki, A., Thrash, P. J., and Jegley, D., “Airframe Development for the Hybrid Wing Body Aircraft,” AIAA Paper 2009932.

${ }^{8}$ Velicki, A., Yovanof, N., Baraja, J., Linton, K., Li, V., Hawley, A., Thrash, P., DeCoux, S., and Pickell, R., "Damage Arresting Composites for Shaped Vehicles-Phase II Final Report, NASA/CR 2011-216880, 2011.

${ }^{9} \mathrm{Wu}, \mathrm{H}$. , and Shaw, P., "Analysis of a Hybrid Wing Body Center Section Test Article", AIAA Paper 2013-1734: 54th AIAA/ASME/ASCE/AHS/ASC Structures, Structural Dynamics, and Materials Conference, Boston, April 2013.

${ }^{10}$ Mukhopadhyay, V: "Hybrid Wing-Body Pressurized Fuselage Modeling, Analysis, and Design for Weight Reduction," AIAA Paper 2012-1999, 53rd AIAA/ASME/ASCE/AHS/ASC Structures, Structural Dynamics, and Materials Conference, Honolulu, April 2012.

${ }^{11}$ Mukhopadhyay, V: "Hybrid Wing-Body Pressurized Fuselage and Bulkhead Design and Optimization," AIAA Paper 20131717, 54th AIAA/ASME/ASCE/AHS/ASC Structures, Structural Dynamics, and Materials Conference, Boston, April 2013. 
${ }^{12}$ Gern, F. H., "Finite Element Based HWB Centerbody Structural Optimization and Weight Prediction, AIAA Paper 20121606, April 2012.

${ }^{13}$ Gern, F., "Conceptual Design and Structural Analysis of an Open Rotor Hybrid Wing Body Aircraft," AIAA Paper 20131688: 54th AIAA/ASME/ASCE/AHS/ASC Structures, Structural Dynamics, and Materials Conference, Boston, April 2013.

${ }^{14}$ Przekop, A., Wu, H. T., Shaw, P., "Nonlinear Finite Element Analysis of a Composite Non-Cylindrical Pressurized Aircraft Fuselage Structure," AIAA-2014-1064, 55th AIAA/ASME/ASCE/AHS/ASC Structures, Structural Dynamics, and Materials Conference, National Harbor, MD, January 2014.

${ }^{15}$ Timoshenko, S., and Krieger, S.W., "Theory of Plates and Shells," McGraw-Hill, New York, $2^{\text {nd }}$ Edition, 1959, pp.197-202.

${ }^{16}$ Timoshenko, S., and Geer, J.M, "Theory of Elastic Stability," McGraw-Hill, New York, Reprinted by Dover, New York, 2 nd Edition, 1989, pp.1-45, pp.362-367.

${ }^{17}$ SolidWorks and SolidWorks Simulation User Manual 2011, SolidWorks Corporation, Dassault Systèmes, Concord, Massachusetts. 